\title{
Knowledge translation for public health in low- and middle- income countries: a critical interpretive synthesis
}

\author{
Catherine Malla* (D), Paul Aylward and Paul Ward
}

\begin{abstract}
Background: Effective knowledge translation allows the optimisation of access to and utilisation of research knowledge in order to inform and enhance public health policy and practice. In low- and middle- income countries, there are substantial complexities that affect the way in which research can be utilised for public health action. This review attempts to draw out concepts in the literature that contribute to defining some of the complexities and contextual factors that influence knowledge translation for public health in low- and middle- income countries.

Methods: A Critical Interpretive Synthesis was undertaken, a method of analysis which allows a critical review of a wide range of heterogeneous evidence, through incorporating systematic review methods with qualitative enquiry techniques. A search for peer-reviewed articles published between 2000 and 2016 on the topic of knowledge translation for public health in low- and middle - income countries was carried out, and 85 articles were reviewed and analysed using this method.

Results: Four main concepts were identified: 1) tension between 'global' and 'local' health research, 2) complexities in creating and accessing evidence, 3) contextualising knowledge translation strategies for low- and middle- income countries, and 4) the unique role of non-government organisations in the knowledge translation process.

Conclusion: This method of review has enabled the identification of key concepts that may inform practice or further research in the field of knowledge translation in low- and middle- income countries.
\end{abstract}

Keywords: Critical interpretive synthesis, Knowledge translation, Low- and middle- income countries, Public health

\section{Background}

There is international recognition that accessing and using health research is a vital component of improving health and reducing health inequities [1]. However, there are substantial complexities that affect the way in which public health research is utilised for action in low and middle income countries (LMICs) [2,3]. The "unacceptable gap between unprecedented knowledge about diseases and their control, and implementation of that knowledge" described by Sanders et al. ([3], p.758), highlights the need for better utilisation of research evidence, particularly in LMICs where the burden of poor health and healthy inequity is high. Analysing the factors that

* Correspondence: mall0051@flinders.edu.au

College of Medicine and Public Health, Flinders University, Sturt Road,

Bedford Park, Adelaide, South Australia 5042, Australia contribute to this gap may contribute to enabling solutions for better utilisation of research in LMICs [3].

Knowledge Translation (KT) - which goes by a host of different terms $[4,5]$ - describes the process of using evidence to make decisions and create action [6]. A commonly used definition of $\mathrm{KT}$ is the Canadian Institutes of Health Research's:

"A dynamic and iterative process that includes synthesis, dissemination, exchange and ethically-sound application of knowledge to improve [health].... provide more effective health services and products and strengthen the health care system.... within a complex system of interactions between researchers and users" [7].

KT provides a mechanism by which the inequities in public health outcomes for LMICs can be reduced [8].

(C) The Author(s). 2018 Open Access This article is distributed under the terms of the Creative Commons Attribution 4.0 International License (http://creativecommons.org/licenses/by/4.0/), which permits unrestricted use, distribution, and 
Research on KT processes can provide an opportunity to examine how $\mathrm{KT}$ can better contribute to reducing these global health inequities [9].

In the context of public health in LMICs, there are substantial complexities that affect the process of KT. Some of these relate to the realities of living in resourcepoor settings, such as low levels of infrastructure and a lack of financial, technical and skilled human resources $[10,11]$. There are also complexities that are borne out of existing structural inequities, such as the historical influence of high-income countries in the field of global health and development, and questions of who and what shape the research agenda, and how this research is used $[3,12-15]$.

The following is a review of the literature on $\mathrm{KT}$ for public health practice and policy in LMICs, focusing on the contextual factors that influence the access to and utilisation of research evidence. This review takes the form of a critical interpretive synthesis (CIS) as described by Dixon-Woods et al. [16] and attempts to draw out themes in the literature that contribute to defining the current state of public health KT in LMICs. It is not intended to be a comprehensive review of what works in $\mathrm{KT}$ in LMICs or to describe $\mathrm{KT}$ processes in LMICs in detail, nor relate KT in LMICs to existing theories and models of $\mathrm{KT}$, some of which has been carried out elsewhere [17-19]. Rather, this review attempts to examine the research on KT processes in LMICs and draw out and analyse some of the complexities and contextual factors that influence $\mathrm{KT}$ in this setting.

\section{Methods}

\section{Literature review type}

The CIS method of analysis is a review type that incorporates systematic review methods with qualitative enquiry techniques to enable the synthesis of a range of types of evidence. From this analysis, 'synthetic constructs' are generated, in order to draw together themes to form new concepts or theories [16, 20, 21]. The CIS method was chosen for this review because it allows for the synthesis of a large and diverse body of literature, followed by the development of concepts through an interpretive analysis [16]. The literature on KT in LMICs is indeed large and diverse, and prior to the analysis, it was not known what the key concepts would be, rather they were allowed to developed during the synthesis, as per the CIS method [16]. The CIS process begins with developing a 'compass question' to initially guide the literature search and analysis, and then an iterative process is followed that enables the question to be modified in response to search results [16]. The compass question that this review began with was "How is evidence accessed and used by policy-makers and public health practitioners for improving public health in low- and middle- income countries?"

\section{Search strategy}

The search strategy was kept intentionally wide-ranging, adopting two broad search terms: "research utilisation" (and related terms) and "LMICs" (and related terms). Consideration was given to narrowing the search through including the search term "public health", however it was felt that this could potentially omit sources that were public health-related but did not specifically use this term. Despite yielding a high number of source articles, this broad search was adopted to maximise the likelihood of capturing all relevant publications. Additional articles were purposively sampled in order to fill conceptual gaps during the course of analysis (in line with the CIS method) such as general papers on research utilisation/knowledge transfer that would form part of the introduction, discussion and the theoretical basis of the literature review. The entire search strategy can be found in Additional File 1. Databases searched were Medline, PubMed, CINAHL, Scopus, Web of Science, Google Scholar, Cochrane Library and PsycINFO. The database searches were limited by English language, humans, and between the years 2000-2016. Table 1 shows the number of articles that were retrieved from each electronic database.

\section{Search results}

A "PRISMA" [22] flow diagram (Fig. 1) summarises the process of article selection. A total of 13,743 articles were retrieved from the electronic database search, and after removal of duplicates the list numbered 10,610. After reading titles and removal of irrelevant articles, 1219 remained. Upon further reading of titles and abstracts of articles that were border-line relevant, a further 770 were removed, leaving 449. At this stage, exclusion criteria were applied using title and abstract, and where required, the full article. Developing exclusion criteria at this stage was necessary as the articles

Table 1 Electronic database search results

\begin{tabular}{ll}
\hline Database & Articles retrieved \\
\hline Medline & 3806 \\
PubMED & 930 \\
PsycINFO & 3145 \\
CINAHL & 3211 \\
Cochrane & 304 \\
Web of Science & 1163 \\
Scopus & 944 \\
Google Scholar & 240 \\
TOTAL & 13,743 \\
\hline
\end{tabular}




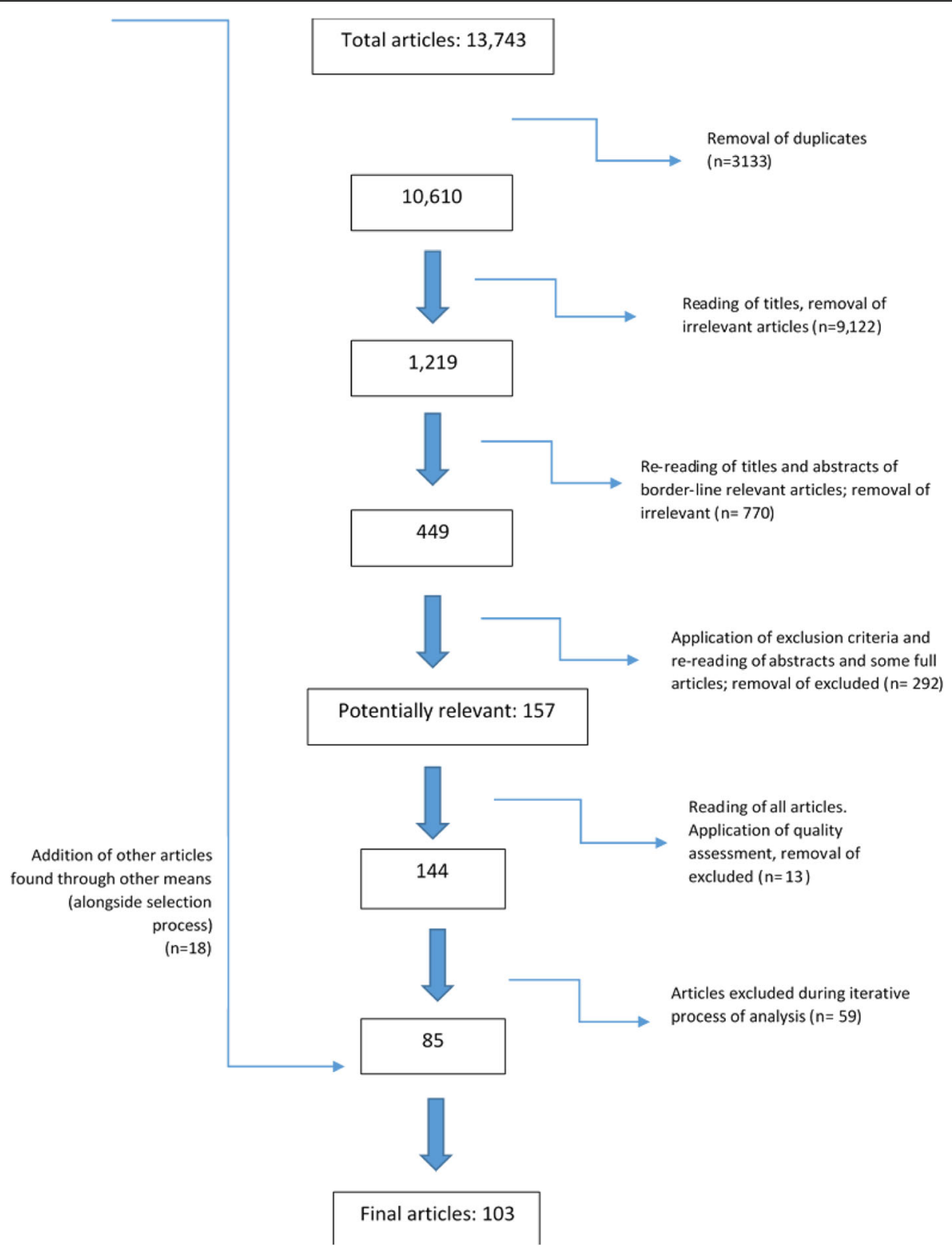

Fig. 1 "PRISMA" diagram outlining process of electronic database and other searching (as per [22])

displayed such a wide range of setting and contexts for $\mathrm{KT}$, and the number of articles for the review needed to be kept at a manageable size. The exclusion criteria that were developed aimed to ensure that the articles chosen were most relevant to the compass question.

Articles that focused on the following were excluded:

1. Clinical practice rather than broader public health

2. Knowledge translation activities directed at clinicians

3. Knowledge translation activities directed at community project beneficiaries
4. Not strictly related to low- and middle-income countries

5. Suggestions that an innovation/trial should be taken up, rather than an actual process

6. Laboratory/biomedical processes

7. Non-health related issues

8. Translating policy into action

9. Protocol papers

After applying the exclusion criteria, 157 potentially relevant articles remained which were each critically examined, and details entered into a data extraction table 
(Additional File 2). The table was developed to capture key concepts from the articles that would allow them to be categorised into themes that could be further developed later into the 'synthetic constructs' required for a CIS. The data extraction table also categorised the articles by type of article, methods and key findings.

At this stage, the articles were also assessed by the first author for quality, utilising a quality assessment tool, drawing on Fane et al.'s [21] use of Attree's grading system from A-C [23] whereby an A grading was for primary research or review with high relevance to the compass question, B was primary research or review with less relevance, and $\mathrm{C}$ was an opinion/commentary, description of programs, or an article that provided background information only. Thirteen papers were excluded at this point. During the process of the CIS analysis of the remaining papers, additional papers $(n=59)$ were excluded, as it became apparent that they were no longer relevant enough to provide insight into the compass question.

Some articles that were not results of the original search were added during the process of analysis $(n=$ 18). These were sourced by scanning the reference lists of the chosen articles for any potentially relevant articles and checking the citations of selected articles using Google Scholar if it was felt that this would provide further insights on a particular concept. Other articles were sourced through Google Scholar in order to fill conceptual gaps.

Types of articles included in the review included primary research (quantitative, qualitative and mixed methods), systematic and scoping reviews, program descriptions and conceptual papers/opinion pieces. Given the large amount of relevant material identified, grey literature was not searched, however specific documents were purposively sourced to capture definitions or the position of a global body such as the World Health Organisation (WHO) $(n=4)$. Table 2 is a summary of the characteristics of the articles, by year and type and method of searching (format modified from Moat, Lavis [20]).

As each article was read, details were added into the data extraction table (Additional File 2).

\section{Analysis}

This review used a CIS approach, and therefore the analysis was an iterative process, with some papers being excluded and added during the analysis process itself, as described above. The analytic approach of a CIS involves the development of 'synthetic constructs' and then a 'synthesising argument' [16]. A 'synthetic construct' interprets and transforms the underlying evidence into a new conceptual form; and then these 'synthetic constructs' are integrated together to form a
Table 2 Characteristics of articles reviewed

\begin{tabular}{|c|c|c|}
\hline \multirow[t]{2}{*}{ Characteristic } & \multicolumn{2}{|l|}{ Number } \\
\hline & Searches & Purposive \\
\hline \multicolumn{3}{|l|}{ Year published } \\
\hline pre- 2000 & 0 & 1 \\
\hline $2000-2005$ & 4 & 4 \\
\hline 2006 & 2 & 0 \\
\hline 2007 & 3 & 0 \\
\hline 2008 & 1 & 1 \\
\hline 2009 & 5 & 1 \\
\hline 2010 & 9 & 3 \\
\hline 2011 & 9 & 3 \\
\hline 2012 & 9 & 2 \\
\hline 2013 & 6 & 1 \\
\hline 2014 & 16 & 1 \\
\hline 2015 & 18 & 0 \\
\hline 2016 & 3 & 1 \\
\hline TOTAL & 85 & 18 \\
\hline \multicolumn{3}{|l|}{ Article type } \\
\hline Conceptual and opinion/commentary & 18 & 5 \\
\hline \multicolumn{3}{|l|}{ Primary Research: } \\
\hline Qualitative & 47 & 2 \\
\hline Quantitative & 4 & 1 \\
\hline Mixed methods & 4 & 1 \\
\hline Reviews & 9 & 5 \\
\hline Description of program & 3 & 0 \\
\hline Grey literature & 0 & 4 \\
\hline TOTAL & 85 & 18 \\
\hline
\end{tabular}

'synthesising argument' that interprets the evidence as a whole $[16,20]$.

The data extraction table was used to draw out the key findings in each paper that related to the compass question. Using NVivo, key findings were coded into general themes which were developed during the process of reading the articles, of which there were 12 at the end of the process.

The groups of key findings coded into each general theme were then re-examined, with the original article consulted again if further clarification was required. Each article within a theme was then re-summarised into one paragraph (some articles had paragraphs in more than one theme), and then using these paragraphs, each theme was summarised into 4-5 key points (using only a few words of a phrase for each key point). All of these key points were written onto one sheet of paper, and from here the synthetic constructs were developed. During the process of writing the 
synthetic constructs, the synthesising argument was constructed. Additional File 3 shows which articles were aligned with each synthetic concept, as well as additional articles that were purposefully sampled to fill conceptual gaps.

\section{Results}

Four synthetic constructs were developed through the analysis of these articles. These include (1) the tension between global and local health research, (2) complexities in creating and accessing evidence, (3) contextualising strategies for KT in LMICs, and (4) the unique role of NGOs in the KT process.

\section{Tension between 'global' and 'local' health research}

Tension between the concepts of 'global' and 'local' is woven throughout the literature describing KT in LMICs. The distinction is made between 'global' evidence and 'local' evidence - 'global' being research on global level health issues or involving global organisations in defining, funding or carrying out research in LMICs; and 'local' being research that is produced at the national or sub-national level by local agencies in LMICs [13, 14, 24-27]. Burchett [28] describes a similar distinction made by public health stakeholders in Ghana between 'big' research (tending to be on national or international scale public health issues) and 'small' research (carried out at the local level, including operational research, evaluations or pilot projects, designed and controlled by local programme managers).

There can be a complex relationship between global and local evidence. Global-level evidence brings an international lens to certain issues such as non-communicable diseases and globalisation, as well as potential links to the latest international thinking and resources to carry out high quality research and provide in-country capacity building [29-31]. However, the importance of local evidence in the development of public health programs is being increasingly recognised, as it ensures that local priorities are recognised, and that research agendas are relevant for the country's policy context and are more connected to realities at the country level $[13,26,29,30$, 32]. The literature describes some programs that have not sufficiently taken on board local-level evidence, to their detriment [14, 25, 30, 33].

Partnerships between international and local organisations have been established as a way to link the production and application of global evidence with local contextual evidence. Strategies such as employing local researchers, directly funding local institutions, building collaborative networks, funding joint initiatives and building research capacity have been employed within such partnerships [24, 31, 34-36]. Some of these partnerships have prioritised and facilitated two-way learning where both partners learn and benefit [24, 31, 35], challenging the "paradigm of uni-directional problem solving" ([24], p.ii54).

However, there is concern that global-local partnerships can be characterised by power imbalances or even exploitation $[13,25,37,38]$. This can mean that research priorities are set by the global partner, resulting in research agendas that have little relevance to local contexts and circumstance, and potential erosion of a country's own research capacity [13, 26, 36, 38]. Although research partnerships may utilise local researchers or organisations, these can be inequitable relationships, where the local partners are in subordinate positions, on the "peripheries" ([13], p.1794, [15]), contributing to "historical inequity in the conduct and access to research" ([15], p.25). Sometimes LMICs are under pressure to undertake certain research as a precondition to receiving funding or loans [36, 37]. Cáceres and Mendoza [13] call for an increase in scrutiny on the growing number of global research collaborations, due to the intricate "political, institutional, economic and cultural variables" ([13], p.1792) that are involved in research in LMICs.

'Global' or 'local' status forms part of the assessment of the trustworthiness of evidence by public health decisionmakers in LMICs, with policymakers acutely aware of the differences in these types of evidence [17, 34, 39, 40]. For some decision-makers, global research has a lower value due to its perceived lack of relevance $[28,40,41]$ whereas local research is believed to be able to provide 'hands-on' evidence and hence has higher value [13, 32, 34, 40, 42]. On the other hand, local research can sometimes be seen to be of low quality due to the lack of skills of local researchers, or because it doesn't provide the conceptual evidence that global research can sometimes provide [41]. Some stakeholders prefer a mixture of the two where one type of evidence can support the other [32, 39, 43]. Trust is important in valuing different types of research - if the researcher, institution or provider of knowledge can be trusted, the evidence is seen to be of higher value [32, 44-46]. Local researchers (those not from international organisations) may be considered trustworthy, depending on their reputation and level of authority [40, 44], however well-known institutions such as the WHO are considered intrinsically trustworthy in some instances $[39,44]$. There is heavy reliance on the trustworthiness of the providers of evidence, as many decision-makers don't have the capacity to critically analyse the research themselves or to be confident in their analysis of a situation $[40,47]$. Knowledge brokers can play a key role as providers of evidence, as people or organisations whose role is to facilitate and mediate between researchers and decision-makers, adapting the research to the local context to reduce barriers to understanding between the two $[5,48,49]$. 
Two forms of evidence that are highly valued across many decision-making settings are local routine data collection and operational research, both forms of 'small' research. These types of data are seen as particularly useful, and often essential, by local stakeholders for several reasons: their ability to provide local context to policy and practice $[28,46,50,51]$; the fact that they can be collected by local researchers, practitioners and other non-academic figures [52]; and the fact that most of the time the agenda for this data collection was set locally, not at a global level [28].

A wide variety of types of evidence is used to inform policy and practice in LMICs $[28,43,46,53,54]$, ranging from formal studies and government reports, to "anything that is done to understand a situation" ([28], p.22). Evidence may be valued or defined by its "relevance, applicability and generalizability to a specific context" rather than necessarily its quality ([54], p.79), and can hold very different meanings depending on the way it is presented, and for which audience [46, 55]. For example, experience and discretionary judgement was the main source of evidence used in updating essential medicines guidelines in Tanzania, as opposed to scientific evidence such as cost-effectiveness studies [56]. Similarly, local burden of disease studies were preferred by countries making decisions on vaccines, rather than global data [39]. The potential of qualitative research evidence to broaden the evidence base in terms of providing context and explanations for quantitative findings in LMICs is discussed briefly in the literature $[28,57]$.

The country in which research is conducted can have an impact on its interpretation and dissemination possibilities. Research produced from low-income countries is less likely to be published than that by a researcher from a high-income country, reducing its dissemination potential [58-60].

\section{Complexities in creating and accessing evidence}

Conducting public health research in some LMICs is limited by weak resource infrastructure and limited institutional capacity. These limitations include little or no government investment for research, low levels of training and skills for researchers, poor academic environments where researchers may work in isolation or combine research with clinical caseloads, limited or no peer review systems, and limited access to research tools such as analysis software $[10,27,38,41,61]$. These limitations contribute to the lack of a research culture sometimes found in LMICs, leaving countries open to "research imperialism" ([12], S4) where external agendas influence research $[12,13,15,25,32]$. They can also lead to limited incentives to carry out research that is policy-related [53] or to incorporate $\mathrm{KT}$ as part of the research process $[62,63]$. Reluctance of local researchers to share data or research results can arise, due to uncertainties about who might be requesting data and why, concerns about data being misrepresented, and the fear of someone else publishing results without permission or appropriately acknowledging the original researcher [60, 64, 65]. Limited understanding of 'Western' approaches to research can also affect applications for research funding, resulting in a possible unfair advantage to researchers from high income countries [13, 28]. These patterns highlight the "balance of prevailing global power, perspectives and interests" ([2], p.1631) in accessing and utilising research evidence.

A globally-defined research agenda has meant that important areas of research have not been necessarily prioritised in LMICs [13], such as research on the social determinants of health $[13,61,66]$, non-communicable diseases, urbanisation and health inequities [67], however this is changing rapidly [68]. Health systems research, another neglected area of public health research in LMICs [69], has tended not to be a priority of 'big' research, but can be beyond the scope of 'small' research $[14,28,30,70]$.

In some LMICs large amounts of data are collected in the form of national health surveys, program monitoring data and operational research $[12,50,51,71]$, creating a reservoir of potential 'valuable' local evidence for decision-making. However, the use of this data is limited by low levels of capacity to analyse it for dissemination for policy and practice $[12,53,72]$ and issues of data quality $[30,41,53,73]$, hence the description "data rich, information poor" ([12], p.S4). Policymakers lament the difficulty in accessing relevant research findings that are of high quality and in digestible formats and they often have limited skills in interpreting evidence [30, 41, 53, 73]. They struggle with being provided an uneven mix of evidence from different sources that is difficult to evaluate, and with being able to ask the right questions for good policymaking [41, 73]. There is a role here for international agencies in supporting operational research and analysis, prompting a call for international support for LMICs to use their operational research data [72].

The unavailability of electronic databases for accessing research evidence due to cost and infrastructure is a significant impediment to its use for public health for some places in LMICs $[17,74,75]$. Some advances have been made in this area, such as the establishment of Hinari $[76,77]$ and similar programs $[52,75,78]$ which are platforms that provide access to scientific literature for little or no cost to health knowledge users in LMICs. These schemes have provided much greater access to online health journals, however there are still some limitations relating to the dissemination of some of these programs, and the provision of practical training in their use [74, 79, 80]. Additionally, infrastructure issues such as 
inadequate hardware, poor Internet connections, and unreliable electricity serve as major impediments to the access and use of evidence [30, 44, 73, 81].

\section{Contextualising strategies for KT in LMICs}

Utilisation of research findings to influence public health policymaking is complex [82] and this is compounded by the many other factors aside from research evidence that influence public health policy $[19,83]$. In LMICs there are particular factors that add to this complexity, including the issues relating to power structures and capacity discussed above. It is important that KT strategies used in LMICs are contextualised for the cultural, political and economic decision-making context $[17,18,38,48]$.

There are many KT models described in the literature [84], however most have been developed in high-income countries and therefore may not be applicable in the context of LMICs [37, 63]. In general, there is a lack of awareness, knowledge and clarity of KT techniques in LMICs $[17,37,62]$. Despite this, there have been attempts to trial and utilise specific KT techniques in LMIC settings, often via a partnership approach. The literature describes a number of these techniques, including: systematic reviews [10], rapid response mechanisms [47], evidence briefs and deliberative dialogues $[85,86]$, KT platforms and formal knowledge networks [17, 87-90], integrated KT [91], the use of knowledge brokers [5, 48, 49] and social knowledge management [92]. Common features for success across these techniques include a strong training or capacity building element, ensuring the cultural, political and economic context is taken into account, and encouraging a collaborative approach across sectors and between researchers and decision-makers.

Factors that facilitate KT in LMICs have been reviewed by Orem et al. [17], who found the most significant factors to be institutional strengthening for KT, the characteristics of the research itself, and partnerships between researchers and policymakers. Building capacity for KT in LMICs requires institutional strengthening of both research and policymaking systems in order to promote a greater use of evidence in policymaking $[13,17,37,50,53,93,94]$. Existing capacity strengthening in these areas is sometimes ad hoc [53] or targeted at individuals rather than at an organisational level [27, 36, 94]. Institutional strengthening in policy-making systems requires resources for infrastructure as well as legitimacy and regulatory support $[53,95]$. It requires technical capacity in critical research skills, knowledge management and in leading $\mathrm{KT}$ processes, stemming from a good understanding of the organisation's capacity for research use in the first place $[50,93,95]$.
The influence of partnerships between researchers and policy-makers provide clear advantage to $\mathrm{KT}$, including both formal and informal knowledge networks and personal relationships [45, 54, 89, 95, 96]. Institutional platforms that allow researchers, policymakers and other stakeholders to engage with each other increases appreciation of each other's processes and challenges [36, 87, 88, 95]. Such platforms may take the form of formal networks (including virtual networks), events, websites, or be a separate entity with an office $[87,88]$. Longer-term links between institutions enables a continuous, rather than ad hoc, exchange of information, strengthening capacity of both the suppliers and the users of evidence $[50,53]$.

A number of strategies have been suggested for optimising the adoption of research findings by policymakers. A review of research characteristics that improve uptake of findings by policymakers [17] found the most effective to be timely, high quality, contextualised evidence that provides economically viable recommendations for policy options, preferably provided by local researchers with high credibility. One way in which research with these characteristics can be produced is through engaging in userdriven research agendas, which result from collaborations between researchers and decision makers [33, 40, 44, 69, 97]. Research that appeals to a political agenda can have a significant effect, such as in Nepal where data on the household cost of a birth attendant presented a novel perspective to health planners and influenced decision-making on maternal and child health policy [42].

Contextualising KT for LMICs can be aided by monitoring and evaluating KT processes, however the lack of systems for doing this in LMICs was noted in this literature $[18,26,62,88,93,98]$, and more widely [6]. The development of robust evaluation frameworks, systems and instruments for KT in LMICs is required for assessing the outcomes and impact of KT activities on changes in behaviour of decision-makers and the structural impact on health systems $[18,62,88,99]$. Some examples of evaluations of KT strategies were found in the literature, however these were few $[88,98,100]$.

\section{The unique role of NGOs in the KT processes}

Non-government organisations (NGOs) in LMICs are in a potentially unique position to be involved in $\mathrm{KT}$, and the literature found that they often carry out KT-related activities as part of their day-to-day activities. NGOs are generally known for their connections to the realities of what is happening at the community level, ability to mobilise communities, and their role in representing and advocating for the vulnerable [52, 93, 101-103], so are well situated to play a role in utilising evidence that promotes equity. NGOs have involvement with a range of KT processes in LMICs including managing, synthesising and 
utilising knowledge for practice and advocacy, disseminating findings, acting as knowledge brokers, implementing research findings, working with partners, advocating with policy makers to implement evidence, and having input into policymaking [17, 24, 38, 52, 93, 95, 98, 101-108].

NGOs in LMICs can have influence over the research process through being involved in research priority setting, resource mobilisation for research, promoting and advocating for relevant research, partnering with international agencies to ensure research relevance and effectiveness and conducting operational research [46, 52, 101-103, 108]. Having NGOs involved in research has been shown to increase the use of research findings in contributing to social development and health equity [103], can increase the role of community in research, and increase the effectiveness of their advocacy efforts [108]. Formal partnerships between NGOs in LMICs and researchers in global health are increasing, and one framework for navigating successful partnerships is described by Olivier et al. [102].

Despite this wide range of roles played by NGOs in $\mathrm{KT}$, there has been little exploration of further capabilities of NGOs in this space in LMICs [3, 93, 95]. NGOs are important stakeholders in the field of public health and may often have potential capacity for a key role in public health KT $[103,107,109,110]$. Supporting local NGOs to better generate and use research evidence has been suggested as an important way to improve KT generally [108-110].

\section{Discussion}

Within the field of public health in general, there are few systems and structures in place to support the promotion and facilitation of KT strategies [82, 111]. In LMICs, structural inequities and limited resources have added barriers to the utilisation of evidence. This review highlights some of the complexities specific to LMICs that can be considered when developing KT strategies in these contexts. The findings from this review show that $\mathrm{KT}$ is influenced by both the nature of knowledge and the context under which these processes occur, and therefore that there is value in identifying and placing importance on these factors. Influencing or acting on such contextual factors may enable "conceptual and strategic ways to bring about changes in knowledge and understanding, or shifts in perception, attitudes and beliefs" ([112], p.189).

This review has identified four 'synthetic constructs' that attempt to interpret some of the research in the area of KT within LMICs, in order to provide a response to the original compass question: "How is evidence accessed and used by policy-makers and public health practitioners for improving public health in low- and middle- income countries?". These 'synthetic constructs' can be viewed as concepts that may provide an insight into some of the complexities of utilising research for action in LMICs. The four concepts identified from the literature were: tension between 'global' and 'local' evidence; complexities in accessing and creating evidence; contextualising strategies for KT in LMICs; and the unique role of NGOs in the KT process. Although these concepts were drawn from a range of different literature on this topic, there are some unifying themes that enable some generalisations from the findings.

The relationship between knowledge and power, or the 'politics of knowledge', was implicit in this literature and influences each concept described above. Power can dictate whose and which forms of knowledge are recognised, valued and used for action, which areas of research are prioritised, and who 'owns' knowledge [3, $13,15]$. This is important when considering the value of knowledge in a globalising world shifting from an "industrial economy to a knowledge economy" ([97], p.35). It is known that the value that stakeholders place on knowledge, evidence and research has an impact on KT processes, and can vary considerably across individuals, organisations, systems and sectors [82]. This review suggests that power and politics can influence this.

The significance of partnerships that influence KT, both global-local partnerships, as well as partnerships between researchers and decision-makers, emerged as a theme across all the concepts that were developed during this review. Analysis of certain aspects of such partnerships may therefore be a valuable undertaking in order to maximise the potential for effective KT.

Capacity building focusing on different aspects of KT was another theme that emerged through the concepts including research capacity; capacity of decision-makers to utilise research evidence; and capacity of various stakeholders to employ KT strategies. It was clear in the literature that the key to effective capacity building in all three of these areas was through institutional strengthening, which should be carried out alongside the capacity building of individuals. This can play a role in building supportive systems and structures for KT in LMICs.

$\mathrm{KT}$ has been described as having the ability to redress global inequities [8] through enabling the use of evidence to improve practice and policy. As described in this review, there are still many issues that can hamper effective utilisation of research in LMIC settings. Analysis of these issues, through research or monitoring and evaluation, in order to improve them, is therefore an important factor in improving health and global inequity. Additionally, there is an acknowledged need for further theoretical development to better understand $\mathrm{KT}$ in order to improve it [113]. Greenhalgh and Wieringa [114] call for research in the field of KT to "move beyond a narrow focus on the 'know-do-gap' to cover a richer agenda" (p. 501). This 
"richer agenda" may include some of the complexities in LMICs described in this review, including the global-local dynamic, links between power and knowledge, and the contextual factors that influence capabilities in LMICs to access, generate and utilise evidence.

\section{Conclusion}

This review has outlined key concepts that arise in the literature around KT for public health in LMICs. Although there are many ways to look at this complex and dynamic area of public health, this review focuses on the themes of global-local interactions, the value placed on evidence, the contextualisation of KT for LMICs, and the unique role of NGOs in this space. This review utilised the CIS method of inquiry, which allowed a flexible approach to interpreting the literature on the topic. This method was useful in allowing the synthesis of disparate themes within a large body of literature and enabled the development of some theoretical concepts relating to the topic. The result of this analysis is a generalised overview of this huge body of literature. Each concept itself could have been analysed to a much greater depth. However, this analysis has drawn out some key theoretical concepts that may inform practice or further research.

\section{Additional files}

Additional file 1: Search Strategy. Search terms used in original search for articles. (DOCX $27 \mathrm{~kb}$ )

Additional file 2: Data Extraction Table. Summary of all articles analysed for the CIS review. (DOCX $51 \mathrm{~kb})$

Additional file 3: Synthetic Construct Analysis. Articles coded against 'synthetic constructs'. (DOCX $38 \mathrm{~kb}$ )

\section{Abbreviations}

CIS: Critical interpretive synthesis; KT: Knowledge translation; LMIC: Low- and middle- income country; NGO: Non-government organisation

\section{Acknowledgements}

The authors would like to thank the four anonymous reviewers who provided very valuable feedback on early drafts of this manuscript.

\section{Funding}

CM received financial support through the Australian Government Research Training Program Scholarship.

\section{Availability of data and materials}

All data generated or analysed during this study are included in this published article (and its supplementary information files).

\section{Authors' contributions}

CM conceived the topic for the CIS review, extracted and analysed the data, and drafted the initial version of the paper. PA and PW provided guidance on conducting a CIS review, contributed to the design of the review, and revised each version critically for intellectual content. All authors approved the final manuscript.

\section{Authors' information}

This review was carried out as part of CM's doctoral studies in public health at Flinders University.
Ethics approval and consent to participate

Not applicable.

\section{Consent for publication}

Not applicable.

\section{Competing interests}

The authors declare that they have no competing interests.

Received: 19 April 2018 Accepted: 27 September 2018

Published online: 22 October 2018

\section{References}

1. World Health Organization. The Bamako call to action on research for health: World Health Organisation; 2008. [12 June 2016]. Available from: http://www.who.int/rpc/news/bamako_call_to_action/en/

2. McCoy D, Sanders D, Baum F, Narayan T, Legge D. Pushing the international health research agenda towards equity and effectiveness. Lancet. 2004;364: 1630-1.

3. Sanders D, Labonte R, Baum F, Chopra M. Making research matter: a civil society perspective on health research. Bull World Health Organ. 2004;82: 757-63.

4. McKibbon KA, Lokker C, Wilczynski NL, Ciliska D, Dobbins M, Davis DA, et al. A cross-sectional study of the number and frequency of terms used to refer to knowledge translation in a body of health literature in 2006: a tower of babel. Implement Sci. 2010;5:16.

5. Norton TC, Howell C, Reynolds C. Exploratory study of the role of knowledge brokers in translating knowledge to action following global maternal and newborn health technical meetings. Public Health. 2016;140: 235-43.

6. Dagenais C, Ridde V, Laurendeau M, Souffez K. Knowledge translation research in population health: establishing a collaborative research agenda. Health Res Policy Syst. 2009;7:28

7. Canadian Institutes of Health Research. Canada 2016 [12 June 2016]. Available from: http://www.cihr-irsc.gc.ca/e/29529.html.

8. Welch $V$, Ueffing $E$, Tugwell P. Knowledge translation: an opportunity to reduce global health inequalities. J Int Dev. 2009;21:1066-82. https://doi.org/ 10.1002/jid.1647.

9. Welch V, Petticrew M, O'Neill J, Waters E, Armstrong R, Bhutta ZA, et al. Health equity: evidence synthesis and knowledge translation methods. Syst Rev. 2013;2(1). https://doi.org/10.1186/2046-4053-2-43.

10. Bennett NR, Cumberbatch C, Francis DK. There are challenges in conducting systematic reviews in developing countries: the Jamaican experience. J Clin Epidemiol. 2015;68:1095-8. https://doi.org/10.1016/j.jclinepi.2014.09.026.

11. Ruggeri K. Disseminating health research in sub-Saharan Africa through journal partnerships. Lancet Glob Health. 2014;2:e193-4. https://doi.org/10. 1016/S2214-109X(13)70158-X

12. Bissell K, Viney K, Brostrom R, Gounder S, Khogali M, Kishore K, et al. Building operational research capacity in the Pacific. Public Health Action. 2014;4:S2.

13. Cáceres CF, Mendoza W. Globalized research and 'national science': the case of Peru. Am J Public Health. 2009;99:1792-8. https://doi.org/10.2105/AJPH. 2008.159236.

14. Goyet S, Touch S, SamAn S, Fassier T, Frutos R, Tarantola A, et al. Gaps between research and public health priorities in low income countries: evidence from a systematic literature review focused on Cambodia. Implement Sci. 2015;10:32

15. Redman-MacLaren ML, MacLaren DJ, Asugeni R, Fa'anuabae CE, Harrington $H$, Muse $A$, et al. "We can move forward": challenging historical inequity in public health research in Solomon Islands. Int J Equity Health. 2010;9:25. https://doi.org/10.1186/1475-9276-9-25.

16. Dixon-Woods M, Cavers D, Agarwal S, Annandale E, Arthur A, Harvey J, et al. Conducting a critical interpretive synthesis of the literature on access to healthcare by vulnerable groups. BMC Med Res Methodol. 2006;6:35.

17. Orem JN, Mafigiri DK, Marchal B, Ssengooba F, Macq J, Criel B. Research, evidence and policymaking: the perspectives of policy actors on improving uptake of evidence in health policy development and implementation in Uganda. BMC Public Health. 2012;12:109. https://doi. org/10.1186/1471-2458-12-109.

18. Siron S, Dagenais C, Ridde V. What research tells us about knowledge transfer strategies to improve public health in low-income countries: a 
scoping review. Int J Public Health. 2015;60:849-63. https://doi.org/10.1007/ s00038-015-0716-5.

19. Hanney SR, Gonzalez-Block MA, Buxton MJ, Kogan M. The utilisation of health research in policy-making: concepts, examples and methods of assessment. Health Res Policy Syst. 2003;1:2.

20. Moat KA, Lavis JN, Abelson J. How contexts and issues influence the use of policy-relevant research syntheses: a critical interpretive synthesis. Milbank Q. 2013;91:604-48.

21. Fane J, MacDougall C, Redmond G, Jovanovic J, Ward P. Young Children's health and wellbeing across the transition to school: a critical interpretive synthesis. Child Aust. 2016;41:126-40.

22. Moher D, Liberati A, Tetzlaff J, Altman DG, The PG. Preferred reporting items for systematic reviews and meta-analyses: the PRISMA statement. PLoS Med. 2009;6:e1000097. https://doi.org/10.1371/journal.pmed.1000097.

23. Attree P. Growing up in disadvantage: a systematic review of the qualitative evidence. Child Care Health Dev. 2004;30:679-89.

24. Adrien A, Thompson LH, Archibald CP, Sandstrom PA, Munro M, Emmanuel $F$, et al. Translating knowledge from Pakistan's second generation surveillance system to other global contexts. Sex Transm Infect. 2013;89(2): ii53-7. https://doi.org/10.1136/sextrans-2012-050774.

25. Banerji D. The World Health Organization and public health research and practice in tuberculosis in India. Int J Health Serv. 2012;42:341-57.

26. Cordero C, Delino R, Jeyaseelan L, Lansang MA, Lozano JM, Kumar S, et al. Funding agencies in low- and middle-income countries: support for knowledge translation. Bull World Health Organ. 2008;86:524-34. https://doi. org/10.2471/BLT.07.040386.

27. Frenk J, Chen L. Overcoming gaps to advance global health equity: a symposium on new directions for research. Health Res Policy Syst. 2011;9:11. https://doi.org/10.1186/1478-4505-9-11.

28. Burchett HE, Mayhew SH, Lavis JN, Dobrow MJ. The usefulness of different types of health research: perspectives from a low-income country. Evidence Policy. 2015;11:19-33. https://doi.org/10.1332/174426514x13990430410723.

29. Hunter DJ, Fineberg HV. Convergence to common purpose in global health. N Engl J Med. 2014;370:1753-5. https://doi.org/10.1056/NEJMe1404077.

30. Jönsson K, Tomson G, Jönsson C, Kounnavong S, Wahlström R. Health systems research in Lao PDR: capacity development for getting research into policy and practice. Health Res Policy Syst. 2007;5:11.

31. Keusch GT, Kilama WL, Moon S, Szlezak NA, Michaud CM. The global health system: linking knowledge with action-learning from malaria. PLoS Med. 2010:7:e1000179. https://doi.org/10.1371/journal.pmed.1000179.

32. Decoster K, Appelmans A, Hill P. A health systems research mapping exercise in 26 low-and middle-income countries: narratives from health systems researchers, policy brokers and policy-makers. Geneva: World Health Organization, The Alliance for Health Policy and Systems Research; 2012. http://www.who.int/alliance-hpsr/alliancehpsr_ backgroundpapermappingexercise.pdf.

33. Tomson G, Paphassarang C, Jönsson K, Houamboun K, Akkhavong K, Wahlström R. Decision-makers and the usefulness of research evidence in policy implementation—a case study from Lao PDR. Soc Sci Med. 2005;61: 1291-9

34. Rodríguez DC, Shearer J, Mariano ARE, Juma PA, Dalglish SL, Bennett S. Evidence-informed policymaking in practice: country-level examples of use of evidence for iCCM policy. Health Policy Plan. 2015;30:ii36-45

35. Cash-Gibson L, Guerra G, Salgado-de-Snyder VN. SDH-NET: a south-northsouth collaboration to build sustainable research capacities on social determinants of health in low-and middle-income countries. Health Res Policy Syst. 2015;13:45.

36. de-Graft Aikins AD, Arhinful DK, Pitchforth E, Ogedegbe G, Allotey P, Agyemang C. Establishing and sustaining research partnerships in Africa: a case study of the UK-Africa academic partnership on chronic disease. Glob Health. 2012;8:29. https://doi.org/10.1186/1744-8603-8-29.

37. Orem JN, Mafigiri DK, Nabudere H, Criel B. Improving knowledge translation in Uganda: more needs to be done. Pan Afr Med J. 2014;17(1):14. https:// doi.org/10.11694/pamj.supp.2014.17.1.3482.

38. Young J. Research, policy and practice: why developing countries are different. J Int Dev. 2005;17:727-34.

39. Burchett HE, Mounier-Jack S, Griffiths UK, Biellik R, Ongolo-Zogo P, Chavez E, et al. New vaccine adoption: qualitative study of national decision-making processes in seven low- and middle-income countries. Health Policy Plan. 2012;27(2):ii5-16. https://doi.org/10.1093/heapol/czs035.
40. Reddy KS, Sahay S. Voices of decision makers on evidence-based policy: a case of evolving TB/HIV co-infection policy in India. AIDS Care 2016:28:397400 4p. doi: https://doi.org/10.1080/09540121.2015.1096889.

41. Hennink M, Stephenson R. Using research to inform health policy: barriers and strategies in developing countries. J Health Commun. 2005;10: 163-80.

42. Ensor T, Clapham S, Prasai DP. What drives health policy formulation: insights from the Nepal maternity incentive scheme? Health Policy. 2009;90: 247-53. https://doi.org/10.1016/j.healthpol.2008.06.009.

43. Onwujekwe O, Uguru N, Russo G, Etiaba E, Mbachu C, Mirzoev T, et al. Role and use of evidence in policymaking: an analysis of case studies from the health sector in Nigeria. Health Res Policy Syst. 2015;13:46. https://doi.org/ 10.1186/s12961-015-0049-0.

44. Albert MA, Fretheim A, Maïga D. Factors influencing the utilization of research findings by health policy-makers in a developing country: the selection of Mali's essential medicines. Health Res Policy Syst. 2007;5:2.

45. Corluka A, Hyder AA, Segura E, Winch P, McLean RK. Survey of argentine health researchers on the use of evidence in policymaking. PLoS One. 2015; 10:e0125711. https://doi.org/10.1371/journal.pone.0125711.

46. Orem JN, Ssengooba F, Macq J, Criel B. Malaria treatment policy change in Uganda: what role did evidence play? Malar J. 2014;13:345. https://doi.org/ 10.1186/1475-2875-13-345

47. Mijumbi RM, Oxman AD, Panisset U, Sewankambo NK. Feasibility of a rapid response mechanism to meet policymakers' urgent needs for research evidence about health systems in a low income country: a case study. Implement Sci. 2014;9. https://doi.org/10.1186/s13012-014-0114-z.

48. Dagenais C, Somé TD, Boileau-Falardeau M, McSween-Cadieux E, Ridde V. Collaborative development and implementation of a knowledge brokering program to promote research use in Burkina Faso, West Africa. Glob Health Action. 2015;8. https://doi.org/10.3402/gha.v8.26004.

49. Waqa G, Mavoa H, Snowdon W, Moodie M, Schultz J, McCabe M, et al. Knowledge brokering between researchers and policymakers in Fiji to develop policies to reduce obesity: a process evaluation. Implement Sci. 2013;8:74. https://doi.org/10.1186/1748-5908-8-74.

50. Brambila C, Ottolenghi E, Marin C, Bertrand JT. Getting results used: evidence from reproductive health programmatic research in Guatemala. Health Policy Plan. 2007;22:234-45.

51. Fabic MS, Choi Y, Bird S. A systematic review of demographic and health surveys: data availability and utilization for research. Bull World Health Organ. 2012;90:604-12. https://doi.org/10.2471/blt.11.095513.

52. Zachariah R, Ford N, Maher D, Bissell K, Van den Bergh R, van den Boogaard $W$, et al. Is operational research delivering the goods? The journey to success in low-income countries. Lancet Infect Dis. 2012;12:415-21. https:// doi.org/10.1016/s1473-3099(11)20309-7.

53. Hawkes N, Aulakh BK, Jadeja N, Jimenez M, Buse K, Anwar I, et al. Strengthening capacity to apply health research evidence in policy making: experience from four countries. Health Policy Plan. 2015;31:161-70.

54. Hyder AA, Corluka A, Winch PJ, El-Shinnawy A, Ghassany H, Malekafzali H, et al. National policy-makers speak out: are researchers giving them what they need? Health Policy Plan. 2010;26:73-82.

55. Storeng KT, Behague DP. "Playing the numbers game": evidencebased advocacy and the technocratic narrowing of the safe motherhood initiative. Med Anthropol Q. 2014;28:260-79. https://doi. org/10.1111/maq.12072.

56. Mori AT, Kaale EA, Ngalesoni F, Norheim OF, Robberstad B. The role of evidence in the decision-making process of selecting essential medicines in developing countries: the case of Tanzania. PLoS One. 2014;9:e84824. https://doi.org/10.1371/journal.pone.0084824.

57. Bosi MLM, Gastaldo D. Building bridges between research, policy and practice in public health. Rev Saude Publica. 2011;45:1197-200<Go to |SI>://WOS:000297802600022.

58. Harris M, Macinko J, Jimenez G, Mahfoud M, Anderson C. Does a research article's country of origin affect perception of its quality and relevance? A national trial of US public health researchers. BMJ Open. 2015;5. https://doi. org/10.1136/bmjopen-2015-008993.

59. Winnik S, Speer T, Raptis DA, Walker JH, Hasun M, Clavien PA, et al. The wealth of nations and the dissemination of cardiovascular research. Int J Cardiol. 2013;169:190-5. https://doi.org/10.1016/j.ijcard. 2013.08.101.

60. Uthman OA, Wiysonge CS, Ota MO, Nicol M, Hussey GD, Ndumbe PM, et al. Increasing the value of health research in the WHO African region beyond 
2015--reflecting on the past, celebrating the present and building the future: a bibliometric analysis. BMJ Open. 2015;5:e006340. https://doi.org/10. 1136/bmjopen-2014-006340.

61. Miranda JJ, Zaman MJ. Exporting 'failure': why research from rich countries may not benefit the developing world. Rev Saude Publica. 2010;44:185-9.

62. Valinejadi A, Sadoughi F, Salehi M. Diabetes knowledge translation status in developing countries: a mixed method study among diabetes researchers in case of Iran. Int J Prev Med. 2016;7:33. https://doi.org/10. 4103/2008-7802.175992.

63. Ssengooba F, Atuyambe L, Kiwanuka SN, Puvanachandra P, Glass N, Hyder AA. Research translation to inform national health policies: learning from multiple perspectives in Uganda. BMC Int Health Hum Rights. 2011;11:1.

64. Hate K, Meherally S, More NS, Jayaraman A, Bull S, Parker M, et al. Sweat, skepticism, and uncharted territory: a qualitative study of opinions on data sharing among public health researchers and research participants in Mumbai, India. J Empir Res Hum Res Ethics. 2015;10:239-50. https://doi.org/ $10.1177 / 1556264615592383$.

65. Jao I, Kombe F, Mwalukore S, Bull S, Parker M, Kamuya D, et al. Research stakeholders' views on benefits and challenges for public Health Research data sharing in Kenya: the importance of trust and social relations. PLoS One. 2015;10. https://doi.org/10.1371/journal.pone.0135545.

66. Borde E, Akerman M, Pellegrini Filho A. Mapping of capacities for research on health and its social determinants in Brazil. Cad Saude Publica. 2014;30: 2081-91.

67. Kendall T, Langer A. Critical maternal health knowledge gaps in low- and middle-income countries for the post-2015 era. Reprod Health. 2015;12:55. https://doi.org/10.1186/s12978-015-0044-5.

68. English KM, Pourbohloul B. Increasing health policy and systems research capacity in low-and middle-income countries: results from a bibliometric analysis. Health Res Policy Syst. 2017;15:64.

69. El-Jardali F, Makhoul J, Jamal D, Ranson MK, Kronfol NM, Tchaghchagian V. Eliciting policymakers' and stakeholders' opinions to help shape health system research priorities in the Middle East and North Africa region. Health Policy Plan. 2010;25:15-27. https://doi.org/10.1093/heapol/czp059.

70. D'Souza C, Sadana R. Why do case studies on national health research systems matter?: identifying common challenges in low- and middleincome countries. Soc Sci Med. 2006;62:2072-8.

71. Zachariah R, Guillerm N, Berger S, Kumar AM, Satyanarayana S, Bissell K, et al. Research to policy and practice change: is capacity building in operational research delivering the goods? Tropical Med Int Health. 2014;19: 1068-75. https://doi.org/10.1111/tmi.12343.

72. Quaglio GL, Ramsay A, Harries AD, Karapiperis T, Putoto G, Dye C, et al. Calling on Europe to support operational research in low-income and middle-income countries. Lancet Glob Health. 2014;2:e308-e10.

73. Cockcroft A, Masisi M, Thabane L, Andersson N. Building capacities of elected national representatives to interpret and to use evidence for healthrelated policy decisions: a case study from Botswana. J Public Health Policy. 2014;35:475-88. https://doi.org/10.1057/jphp.2014.30.

74. Chen $\mathrm{YL}$, Yang $\mathrm{KH}$. Avoidable waste in the production and reporting of evidence. Lancet. 2009;374:786. https://doi.org/10.1016/S0140-6736(09)61591-9.

75. Tharyan P. Don't just do it, do it right: evidence for better health in low and middle income countries. Ceylon Med J. 2010;55:1-4.

76. Anyaoku EN, Anunobi CV. Measuring HINARI use in Nigeria through a citation analysis of Nigerian journal of clinical practice. Health Inf Libr J. 2014;31:148-55. https://doi.org/10.1111/hir.12056.

77. World Health Organisation. Hinari Research for Health 2018 [July 2018]. Available from: http://www.who.int/hinari/en/.

78. Hawkes N. Elsevier improves access to its products in 100 developing countries. BMJ. 2012;345:e6283. https://doi.org/10.1136/bmj.e6283.

79. Glover SW, Dema R, Yangzon P, Sonam K, Gleghorn C. A review of health and access to health information in Bhutan. Health Inf Libr J. 2006;23:290-3.

80. Yousefi-Nooraie R, Rashidian A, Nedjat S, Majdzadeh R, Mortaz-Hedjri S, Etemadi $A$, et al. Promoting development and use of systematic reviews in a developing country. J Eval Clin Pract. 2009;15:1029-34. https://doi.org/10. 1111/j.1365-2753.2009.01184.x.

81. Mbonye AK, Magnussen P. Translating health research evidence into policy and practice in Uganda. Malar J. 2013;12:274. https://doi.org/10.1186/14752875-12-274.

82. Armstrong $R$, Waters $E$, Moore $L$, Dobbins M, Pettman $T$, Burns $C$, et al. Understanding evidence: a statewide survey to explore evidence-informed public health decision-making in a local government setting. Implement Sci. 2014;9(1):188.

83. Walugembe DR, Kiwanuka SN, Matovu JK, Rutebemberwa E, Reichenbach L. Utilization of research findings for health policy making and practice: evidence from three case studies in Bangladesh. Health Res Policy Syst. 2015;13:26. https://doi.org/10.1186/s12961-015-0015-x.

84. Tabak RG, Khoong EC, Chambers DA, Brownson RC. Bridging research and practice: models for dissemination and implementation research. Am J Prev Med. 2012;43:337-50.

85. Moat KA, Lavis JN, Clancy SJ, El-Jardali F, Pantoja T. Evidence briefs and deliberative dialogues: perceptions and intentions to act on what was learnt. Bull World Health Organ. 2014;92:20-8. https://doi.org/10.2471/blt. 12.116806.

86. Rosenbaum SE, Glenton C, Wiysonge CS, Abalos E, Mignini L, Young T, et al. Evidence summaries tailored to health policy-makers in low-and middleincome countries. Bull World Health Organ. 2011;89:54-61.

87. Kasonde JM, Campbell S. Creating a knowledge translation platform: nine lessons from the Zambia forum for Health Research. Health Res Policy Syst. 2012;10:31. https://doi.org/10.1186/1478-4505-10-31.

88. El-Jardali F, Lavis J, Moat K, Pantoja T, Ataya N. Capturing lessons learned from evidence-to-policy initiatives through structured reflection. Health Res Policy Syst. 2014;12:2. https://doi.org/10.1186/1478-4505-12-2.

89. Yazdizadeh B, Majdzadeh R, Alami A, Amrolalaei S. How can we establish more successful knowledge networks in developing countries? Lessons learnt from knowledge networks in Iran. Health Res Policy Syst. 2014;12:63. https://doi.org/10.1186/1478-4505-12-63.

90. Lavis JN, Guindon GE, Cameron D, Boupha B, Dejman M, Osei EJ, et al. Bridging the gaps between research, policy and practice in low- and middle-income countries: a survey of researchers. CMAJ. 2010;182:E350-61. https://doi.org/10.1503/cmaj.081164.

91. Yehia F, El Jardali F. Applying knowledge translation tools to inform policy: the case of mental health in Lebanon. Health Res Policy Syst. 2015;13:29. https://doi.org/10.1186/s12961-015-0018-7.

92. Sullivan TM, Limaye RJ, Mitchell V, D'Adamo M, Baquet Z. Leveraging the power of knowledge management to transform Global Health and development. Global Health Sci Pract. 2015;3:150-62. https://doi.org/10. 9745/GHSP-D-14-00228.

93. Hamel N, Schrecker T. Unpacking capacity to utilize research: a tale of the Burkina Faso public health association. Soc Sci Med. 2011;72:31-8. https:// doi.org/10.1016/j.socscimed.2010.09.051.

94. Gadsby EW. Research capacity strengthening: donor approaches to improving and assessing its impact in low-and middle-income countries. Int J Health Plann Manag. 2011;26:89-106.

95. Orem JN, Marchal B, Mafigiri DK, Ssengooba F, Macq J, Da Silveira VC, et al. Perspectives on the role of stakeholders in knowledge translation in health policy development in Uganda. BMC Health Serv Res. 2013; 13(1):324.

96. Shearer JC, Dion M, Lavis JN. Exchanging and using research evidence in health policy networks: a statistical network analysis. Implement Sci. 2014;9: 126. https://doi.org/10.1186/s13012-014-0126-8.

97. Lapaige V. "Integrated knowledge translation" for globally oriented public health practitioners and scientists: framing together a sustainable transfrontier knowledge translation vision. J Multidiscip Healthc. 2010; 3:33-47.

98. Dagenais C, Queuille L, Ridde V. Evaluation of a knowledge transfer strategy from a user fee exemption program for vulnerable populations in Burkina Faso. Glob Health Promot. 2013;20:70-9. https://doi.org/10.1177/ 1757975912462416.

99. Sumner A, Crichton J, Theobald S, Zulu E, Parkhurst J. What shapes research impact on policy? Understanding research uptake in sexual and reproductive health policy processes in resource poor contexts. Health Res Policy Syst. 2011;9:S3. https://doi.org/10.1186/1478-4505-9-s1-s3.

100. Johnson NA, Lavis JN. Procedures manual for the" evaluating knowledgetranslation platforms in low-and middle-income countries" study. 2009.

101. Drake JK, Hutchings JE, Elias CJ. Making evidence work for communities: the role of nongovernmental organizations in translating science to programs. J Women's Health (Larchmt). 2010;19:2119-24. https://doi. org/10.1089/jwh.2010.2050

102. Olivier C, Hunt MR, Ridde V. NGO-researcher partnerships in global health research: benefits, challenges, and approaches that promote success. Dev Pract. 2016;26:444-55. 
103. Delisle H, Roberts JH, Munro M, Jones L, Gyorkos TW. The role of NGOs in global health research for development. Health Res Policy Syst. 2005;3:3.

104. Orem JN, Nanyunja M, Marchal B, Criel B, Ssengooba F. The roles and influence of actors in the uptake of evidence: the case of malaria treatment policy change in Uganda. Implement Sci. 2014;9:150. https://doi.org/10. 1186/s13012-014-0150-8.

105. Siminerio L, Mbanya JC. Translating diabetes research into global communities. Diabetes Res Clin Pract. 2011;93:443-5. https://doi.org/10. 1016/j.diabres.2011.07.010.

106. Woelk G, Daniels K, Cliff J, Lewin S, Sevene E, Fernandes B, et al. Translating research into policy: lessons learned from eclampsia treatment and malaria control in three southern African countries. Health Res Policy Syst. 2009;7:31.

107. Zachariah R, Draquez B. Operational research in non-governmental organisations: necessity or luxury? Public Health Action. 2012;2:31.

108. Zachariah R, Ford N, Draguez B, Yun O, Reid T. Conducting operational research within a non governmental organization: the example of Medecins sans Frontieres. Int Health. 2010;2:1-8.

109. Kothari A, Armstrong R. Community-based knowledge translation: unexplored opportunities. Implement Sci. 2011;6(1):59.

110. Wilson MG, Lavis JN, Travers R, Rourke SB. Community-based knowledge transfer and exchange: helping community-based organizations link research to action. Implement Sci. 2010;5:33.

111. LaRocca R, Yost J, Dobbins M, Ciliska D, Butt M. The effectiveness of knowledge translation strategies used in public health: a systematic review. BMC Public Health. 2012;12(1):751.

112. Davies $H$, Nutley S, Walter I. Why 'knowledge transfer'is misconceived for applied social research. J Health Serv Res Policy. 2008;13:188-90.

113. El-Jardali F, Fadlallah R. A call for a backward design to knowledge translation. Int. 2015;4:1-5.

114. Greenhalgh T, Wieringa S. Is it time to drop the 'knowledge translation'metaphor? A critical literature review. J R Soc Med. 2011;104:501-9.

Ready to submit your research? Choose BMC and benefit from:

- fast, convenient online submission

- thorough peer review by experienced researchers in your field

- rapid publication on acceptance

- support for research data, including large and complex data types

- gold Open Access which fosters wider collaboration and increased citations

- maximum visibility for your research: over $100 \mathrm{M}$ website views per year

At $\mathrm{BMC}$, research is always in progress.

Learn more biomedcentral.com/submissions 